\title{
CIDADE EDUCATIVA: REFLEXÕES SOBRE EDUCAÇÃO, CIDADANIA, ESCOLA E FORMAÇÃO HUMANA
}

\section{EDUCATION CITY: REFLECTIONS ON EDUCATION, CITIZENSHIP, SCHOOL AND HUMAN FORMATION}

\author{
Priscila de Souza Chisté, Antonio Donizetti Sgarbi
}

Instituto Federal do Espírito Santo

E-mail: priscilachiste.ufes@gmail.com, donizettisgarbi@gmail.com

\section{Resumo}

O texto discute as relações entre escola, cidade, educação e cidadania, com vistas a contribuir com a prática pedagógica em espaços não formais e com a formação do educador. Para refletir sobre essa temática, norteia-se pelas seguintes questões: Que estratégias podem ser pensadas para que a Cidade contribua com reflexões e com a transformação da realidade? Como pode a Cidade contribuir com o processo humanizador dos sujeitos? Quais são os caminhos para construirmos uma escola cidadã em diálogo com uma cidade educativa? Diante dos desafios enunciados, utiliza como metodologia a pesquisa bibliográfica, tendo em vista que analisa leis, artigos e livros que versam sobre o assunto. Trata-se, portanto, de um estudo teórico que visa colaborar com as discussões relacionadas com a cidade e com o seu potencial educativo a partir de referenciais teóricos que dialogam com a pedagogia progressista.

Palavras-chave: cidade educativa. escola cidadã. formação do educador. espaços não formais.

\begin{abstract}
The paper discusses the relationship between school, city, education and citizenship, in order to contribute with the pedagogical practice in non-formal spaces and with the formation of the educator. To reflect on this theme, guides by the following questions: what strategies can be designed so that the city contribute with reflections and the transformation of reality? How can the city contribute with the humanizing process of the subject? What are the ways to build a citizen school in dialogue with an educational city. On the challenges set out, uses as the bibliographical research methodology, with a view to analyzing laws, articles and books about the subject. It is thus a theoretical study that aims to collaborate with related discussions with the city and with their educational potential from theoretical references dialogue with progressive pedagogy.
\end{abstract}

Palavras-chave: education city. citizen school. educator training. non-formal spaces. 


\section{INTRODUÇÃO}

Nas últimas décadas, face à progressiva procura por uma maior integração dos projetos culturais e institucionais que se associam às escolas e às comunidades locais, proliferaram propostas como: Sociedade Pedagógica (BEILLEROT, 1985), Sociedade Educativa (HÚSEN, 1988), Sociedade Educadora (AGAZZI, 1965) e Cidade Educadora (FAURE, 1977). Todas essas iniciativas põem em relevo as potencialidades educativas da cidade e de seus diferentes agentes. O relatório publicado pela Unesco em 1973, sob a coordenação de Faure, acolhe a ideia de cidade educadora como uma prospecção da educação para os últimos anos do século XX (VILLAR, 2001).

No entanto, é preciso lembrar que a Unesco foi constituída logo após a Segunda Guerra Mundial por alguns países interessados em "ajudar" os países mais devastados pela guerra. Como membro de grande ajuda, a Unesco contou com o Banco Mundial, que desde então busca "contribuir" com a educação nos países que necessitam se adequar ao contexto de globalização do mercado. Várias propostas estão sendo impostas para que as adequações sejam efetivadas, dentre elas a proposição "Cidade Educadora".

Algumas ações foram sugeridas na tentativa de implementar essa ideia em diferentes cidades. Em 1990, em Barcelona, na Espanha, foi realizado o I Congresso Internacional das Cidades Educadoras. Esse congresso aprovou uma Carta de princípios básicos que caracterizam uma cidade que educa. $\mathrm{O}$ documento traz a premissa de que a cidade deve deixar de ser um mero recurso pedagógico da escola para converter-se em um verdadeiro agente educativo, em uma fonte de aprendizagem, de sabedoria e convivência. Posteriormente, em 1994, este movimento formalizou-se como Associação Internacional (AICE), oficialmente criada no $3^{\circ}$ Congresso das Cidades Educadoras, o qual decorreu em Bolonha, Itália. Algumas cidades brasileiras membros da AICE são: Vitória, Belo Horizonte, Campo Novo do Parecis, Caxias do Sul, Cuiabá, Dourados, Gravataí, Jequié, Montes Claros, Piracicaba, Porto Alegre, Santo André, Santos, São Bernardo do Campo, São Carlos, São Paulo e Sorocaba. 
Para além da perspectiva incentivada pela Unesco, que visa à ampliação e ao reforço da sociedade capitalista, pela via de se delegar à sociedade civil a responsabilidade de implementar e executar políticas sociais, é preciso pensar no potencial emancipador da Cidade. Qual potencial transformador da realidade reificada tem a Cidade? Que estratégias podem ser pensadas para que a Cidade contribua com reflexões e com a transformação da realidade? Como pode a Cidade contribuir com o processo humanizador dos sujeitos? Quais são os caminhos para construirmos uma escola cidadã em diálogo com uma cidade educativa?

Para pensar sobre essas questões, propomos iniciar nossas reflexões, debruçando-nos sobre o conceito de educação a partir de referenciais teóricos que se conciliam com a pedagogia progressista. 


\section{EDUCAÇÃO}

A Educação é o processo de reprodução social que tem como função construir, direta e intencionalmente, em cada indivíduo, a humanidade que é produzida histórica e coletivamente pelos homens (SAVANI, 1997). É no curso das relações sociais que os indivíduos produzem, apropriam-se, transformam as diferentes atividades práticas e simbólicas em circulação na sociedade em que vivem e as internalizam como modos de ação/elaboração próprios, constituindo-se como sujeitos. Assim, para o indivíduo se constituir como ser humano, é preciso que internalize as produções humanas que foram sistematizadas na trajetória da humanidade (a cidade é um exemplo dessas produções) (CHISTÉ, 2013).

Dentre as práticas sociais, a Educação é mediação que funciona como organizadora e transmissora de ideias, medeia as ações executadas no contexto educativo. A educação pode servir de mediação entre ações sociais, pode representar, como prática pedagógica, uma mediação entre ideias, pois revela a posse de uma ideia anterior que move a ação. Com o fim da ação, novas ideias surgem como possibilidades de iluminar a prática pedagógica seguinte. Esse duplo movimento permite entender como, sem a mediação, a educação acaba formando um universo à parte, existente independentemente da ação. A mediação permite superar o aparente fosso existente entre as ideias e a ação (CURY, 2000).

A partir dessas premissas é possível pensar que a Educação é um fato existencial. Refere-se ao modo como o homem se faz homem. A Educação configura o homem em toda a sua realidade. É o processo pelo qual o homem constrói a sua essência. Contudo, sua realização depende de situações históricas objetivas, das forças sociais presentes, de seu conflito, dos interesses em causa, entre outros aspectos (PINTO, 1997).

O direito à Educação está assegurado pela Constituição Federal brasileira, em seu artigo 205: "A educação, direito de todos e dever do Estado e da família, será promovida e incentivada com a colaboração da sociedade, visando ao pleno desenvolvimento da pessoa, seu preparo 
para o exercício da cidadania e sua qualificação para o trabalho". Contudo, tal direito está sob ameaça em tempos de crescente mercantilização da educação. Isso porque o Estado está deixando de garantir esse direito e entregando a educação às demandas do Mercado. Gadotti (2005) ajuda-nos a refletir sobre o assunto ao dizer que as Indústrias do Conhecimento oferecem os mais variados pacotes educacionais para todos os gostos, em acirradas disputas mercantis movidas pelo marketing educacional, vendendo educação como se vende um sabonete. Nesse contexto de mercantilização da Educação, os educandos são os maiores prejudicados e, consequentemente, têm suas formações prejudicadas e alijadas de uma perspectiva crítica e emancipatória.

Tal perspectiva se materializa quando a Educação é entendida como atividade na qual educadores e educandos, mediatizados pela realidade, aprendem e extraem dela o conteúdo da aprendizagem, atingindo um nível de consciência elevado, capaz de impulsioná-los a atuar na realidade visando à transformação social.

\subsection{Educação Formal, Informal e Não Formal}

Podemos discutir Educação de vários modos, mantendo a premissa de que ela é sempre mediação. Em sentido amplo, a Educação pode ser pensada como processo contínuo, que contribui com a transformação das pessoas, com a relação que estabelecem com elas mesmas, com os outros e com o mundo. Isso, de maneira geral, acontece na cidade. Trata-se de uma educação que se desenvolve entre cidadãos entendidos como pessoas. Compreendemos pessoa cidadã como aquela que possui o empoderamento no sentido freireano, aquela que "realiza por si mesma as mudanças e ações que a levam a evoluir e a se fortalecer" (VALOURA, s/d, p. 1).

Em sentido mais restrito, a educação escolar pode ser entendida como

[...] um processo educacional intencional, ele envolve escolhas por parte dos educadores. Daí o fato de a educação escolar nunca ser neutra. E como está relacionada à "formação" de pessoas para viverem em uma sociedade, 
ela é política. Ela é uma forma de intervenção intencional na maneira de funcionar da sociedade, porque procura influenciar algumas formas de ser dos educandos que são julgadas "convenientes" para a sociedade na qual a educação escolar está inserida (LORIERI, 2006, p. 91).

Outra forma de se discutir as diversas dimensões da educação é classificá-la como educação formal, informal e não formal. Cotidianamente, ocorrem situações que não foram intencionadas para serem educativas, mas que efetivamente geram efeitos educativos. Nesse sentido, a Educação Informal seria constituída pelo conjunto de processos e fatores que geram efeitos educativos sem que tenham sido expressamente configurados para esse fim, ou seja, não se caracteriza por uma intervenção pedagógica intencionada e consciente, mas sim como um processo formativo que ocorre informalmente. Ela se caracteriza por não se ajustar a formas institucionalmente determinadas e explícitas.

A Educação Formal, de acordo com Gadotti (2005), tem objetivos claros e específicos e é representada principalmente pelas escolas e universidades. "Ela depende de uma diretriz educacional centralizada no currículo, com estruturas hierárquicas e burocráticas, determinadas em nível nacional, com órgãos fiscalizadores dos ministérios da educação" (GADOTTI, 2005, p. 02). Trata-se da educação escolar anteriormente descrita.

Já a Educação Não Formal é menos hierárquica, menos burocrática. Não necessita seguir um sistema sequencial de progressão e pode ter duração variável. Ela pode ser compreendida como toda atividade educacional organizada, sistematizada e executada fora do quadro do sistema formal de ensino, com vistas a oferecer determinados tipos de ensino a subgrupos da população. Gadotti (2005) alerta que muitas definições de educação não formal são tendenciosas, pois se definem em oposição a educação formal. Como se a educação não formal se constituísse pela ausência. Essa visão toma a educação formal como o único modelo, como se a educação formal escolar não pudesse aceitar o extra-escolar.

Na busca por redimensionar essa discussão, Gadotti (2005) pontua que o espaço da escola é 
marcado pela formalidade, pela regularidade e sequencialidade. Não obstante, a educação não formal é também uma atividade organizada e sistematizada, mas levada a efeito fora do sistema formal. "Na educação não formal a categoria espaço é tão importante como a categoria tempo" (GADOTTI, 2005, p. 02). Isso porque o tempo da aprendizagem na educação não formal é flexível, respeitando as diferenças e as capacidades de cada sujeito. Além disso, pode ser criada e recriada em múltiplos espaços.

Desse modo, observa-se que a tipologia que subdivide os contextos educativos em formais, não formais e informais muitas vezes não conseguem abarcar a mobilidade do processo educativo. Mais do que propor o enquadramento das práticas educacionais em determinada modalidade conceitual, é necessário buscar trilhas do aprender nas quais se possa perceber situações que revelam a educação como um amplo processo social que não se resume aos cotidianos institucionais de aprendizagem (BRANDÃO, 1986). Não se trata de se opor à educação formal ou à não formal. O ponto em questão é conhecer melhor suas potencialidades e harmonizá-las em benefício de todos. Acreditamos que essa questão começa a se esclarecer quando entendemos a educação em sentido amplo e a educação em sentido restrito. Quando discutimos, por exemplo, a relação entre cidade e escola que educam e se educam mutuamente. Quando temos uma Escola Cidadã e uma Cidade Educativa em constante diálogo (GADOTTI, 2005).

Ao consideramos essa perspectiva, é preciso ficar alerta aos conceitos dicotômicos. Cabe assumirmos a postura de que todos os espaços possuem potencial educativo. Uns mais outros menos. Se pensarmos que "assim como todo homem é filósofo, todo homem é cientista [...]" (GRAMSCI, 1984, p. 41), todo ser humano é um educador ou um educando. 0 que define isso é a postura de cada um. Depende do modo como se comporta no ambiente em que vive ou no que está a conhecer. É assim que os espaços passam a ser realmente espaços educativos. 


\section{A HISTÓRIA E FORMAS DE INTERPRETAR A CIDADE}

Se toda Cidade tem potencial educativo e se cada cidade é formada por inúmeros espaços, logo cada espaço tem potencial educativo. Se partirmos desse silogismo à moda da lógica aristotélica, podemos pensar que, para que isso possa ser explicitado, cabe fazermos uma reflexão sobre a cidade e a forma como devemos encará-la para que cada um de seus espaços revele o seu potencial de espaço educador. Para tanto, a seguir, apresentaremos alguns apontamentos sobre a História das Cidades.

\subsection{Apontamentos sobre História das Cidades}

Uma das explicações relacionadas à gênese da cidade está relacionada ao modo de produção agrícola. O cultivo da terra permitiu que as sociedades antigas produzissem mais alimentos, com isso, a população humana cresceu rapidamente. Em consequência do aumento da população, houve a necessidade de se ampliar as áreas cultivadas e desenvolver novas técnicas para melhorar a produtividade do solo. As pequenas comunidades e aldeias começaram a se unir para construir sistemas de irrigação e aproveitar melhor as margens férteis dos rios. A união das aldeias provocou a formação de cidades.

As primeiras cidades formaram-se nas proximidades de grandes rios, pois a água era essencial à agricultura. Elas surgiram entre 3.500 e 3.000 a.C., nos vales dos rios Nilo, no Egito e Tigre e Eufrates, na Mesopotâmia; posteriormente, mais ou menos em 2.500 a.C., no vale do rio Indo, na Índia; e, por volta de 1.500 a.C., na China.

As cidades tinham duas características básicas: a divisão social do trabalho e a centralização política. Nas cidades, os cidadãos passaram a ser classificados de acordo com a sua função, incluindo os sacerdotes, os escribas, os mercadores, os artesãos, os soldados, os camponeses, os escravos domésticos, os estrangeiros. A divisão do trabalho e as desigualdades de riquezas entre os cidadãos criaram a necessidade de leis e de forças capazes de fazer cumprir as leis. 
A liderança natural do grupo, que nas aldeias era exercida pelos mais velhos e sábios, cedeu lugar ao governo de um só homem, geralmente o principal administrador do templo ou um grande chefe guerreiro, surgindo assim a Cidade-Estado: uma organização de pessoas com plena autoridade sobre a população, que podia, por exemplo, criar e cobrar impostos, organizar a defesa, fazer as leis e julgar os crimes.

A maior parte da população da cidade trabalhava na agricultura e na criação de animais. Com a evolução desses processos, a produção começou a sobrar, gerando os excedentes. Esses excedentes puderam ser trocados com os excedentes de outros povos, dando origem ao comércio. A grande quantidade de alimentos abastecia o grupo de trabalhadores que se dedicava à prestação de serviços (médicos, soldados, sacerdotes) ou à fabricação de objetos (cerâmica, instrumento de metal, tecidos). A especialização do trabalho permitiu duas inovações técnicas muito importantes: a confecção de tecidos e a cerâmica, artigos facilmente comercializáveis.

Com a evolução do comércio, surgem as cidades urbanas, que emergem rapidamente a partir da Revolução Industrial. Massas humanas deixam as suas áreas campesinas em busca de novas oportunidades de emprego e de vida. Com isso, os locais em torno das indústrias passaram a ser ocupados pelas pessoas que ali trabalhavam. Armazéns para venda de alimentos, locais para a diversão da massa trabalhadora, como bares e bordéis, surgem também, desenhando novos espaços e criando assim as pequenas cidades.

Na medida em que o processo de industrialização foi se ampliando, as cidades foram adquirindo novas configurações. Muitas cidades surgiram a partir dos burgos, que eram conjuntos de habitações fortificadas que serviam de residência para os burgueses. Com a dinamização da economia nas cidades, em função do comércio, muitas pessoas começaram a deixar o campo para tentar a vida nos centros urbanos. Desse modo, nos séculos XIV e XV, a Europa passou por um importante processo de êxodo rural. 
Com mais pessoas morando nas cidades europeias, as necessidades e transformações aumentaram muito. Começaram a surgir novas profissões e oportunidades de trabalho. $\mathrm{O}$ dinheiro, principalmente moedas de ouro e prata, começou a circular com maior intensidade.

Os cambistas, por exemplo, ganharam espaço na sociedade, pois, com o avanço do comércio, eram necessárias as trocas de moedas para o bom funcionamento das relações comerciais entre as várias regiões da Europa. Nesta época, cada cidade ainda possuía um tipo de moeda diferente.

Surgiram os banqueiros para garantir e proteger, com segurança, as fortunas dos prósperos burgueses. Cheques, cartas de créditos e outras modalidades financeiras começaram a ser utilizadas neste período. Os artesãos e comerciantes começaram a se organizar como uma maneira de obterem melhores resultados em suas atividades. Os artesãos criaram as corporações de ofício, enquanto os comerciantes estabeleceram as guildas.

Por conseguinte, a camada dos comerciantes e artesãos livres já não dependia mais da terra, e sim de atividades puramente urbanas. Dos artesãos e comerciantes mais poderosos, surgem aqueles que passam a investir grandes somas de riqueza em manufaturas. Essas manufaturas, na verdade, foram as primeiras indústrias, ainda primitivas, mas que já se caracterizavam pela divisão interna de funções, o trabalho parcelado em inúmeras atividades, a partir da introdução de novas e melhores máquinas e técnicas.

Cada operador de máquinas já não elaborava o produto por inteiro, mas apenas uma peça que, somada às peças de outros operadores isolados, dava origem ao produto final. Assim ocorre a divisão social do trabalho. Com ela a produção voltada para o mercado começou a ganhar espaço, incentivando as trocas monetárias, a organização empresarial, o espírito de lucro, seguida pelas várias fases da Revolução Industrial, dando origem ao Capitalismo. 
No mundo moderno, as Cidades vão se complexificando cada vez mais. Multiplicam-se as historiografias sobre a Cidade, as formas de ver e compreender a Cidade, tanto a do passado como a nova. Assim sendo, trataremos de alguns dos olhares que se pode ter sobre a Cidade, antes, porém, deixamos uma palavra sobre as variadas visões sobre a realidade.

\subsection{Os diversos olhares sobre a realidade}

Os apontamentos anteriores são uma forma de se desenvolver uma historiografia das cidades. Existem outras, mas tudo depende do olhar que se tem sobre a realidade. Todo espaço da cidade é potencialmente educativo. O que torna espaços efetivamente educativos, como bairros, ruas, casas, prédios, mercados, praças, árvores, praias, recantos, bares, igrejas, campos de futebol etc., é o olhar que se tem sobre eles. Quem se interessa pela educação tem um olhar pedagógico diante das coisas, assim como um filósofo que se espanta diante das coisas, ou um artista que capta a totalidade do real, enxergando aquilo que está além das aparências. Assim, aquele que tem um olhar pedagógico percebe logo o potencial educador de um espaço ou de uma situação.

Conta-se que Sócrates (469 - 399 a.C.) gostava de descansar a cabeça passeando pelo mercado de Atenas e, quando algum dos vendedores o assediava, ele dizia: "[...] estou apenas observando quanta coisa existe de que não preciso para ser feliz" (FREI BETTO, 2011). Essa era a forma não consumista de Sócrates passear pelo mercado. Pouco antes dele, Pitágoras (571 - 496 a.C.) dizia que vários tipos de pessoas frequentavam a festa mais importante da Grécia, os jogos olímpicos: os comerciantes que, voltados para os seus interesses, não se preocupavam com as disputas; os atletas que iam às festas interessados nas competições; os artistas voltados para as diversas formas de dança, poesia, música ou teatro; "os que iam apenas para contemplar para avaliar o desempenho e julgar o valor dos que ali se apresentavam. Esse terceiro tipo de pessoa, dizia Pitágoras, é como o filósofo" (CHAUÍ, 1999, p. 20). Assim como a forma de olhar as coisas faz o filósofo ou o artista, também a forma de olhar o mundo faz o educador. 
Isso remete ao pensamento de outro filósofo, não da antiguidade, mas do final do século XIX, Nietzsche (1844 - 1900), que, em sua obra "Humano, demasiado humano II", no aforismo 228, "Os viajantes e seus graus", afirma:

Entre os viajantes devemos distinguir cinco graus: os do primeiro, o mais baixo, são aqueles que viajam e são vistos - são viajados, na verdade, e praticamente cegos; os do grau seguinte vêem a si mesmos no mundo, realmente; os terceiros vivenciam algo como consequência do que vêem; os quartos assimilam o vivenciado e o carregam consigo; há, por fim, alguns indivíduos de elevada energia, que, após terem vivenciado e assimilado o que foi visto, têm de necessariamente dar-lhe vida de novo, em obras e ações, tão logo retornem para casa. - De modo igual a esses cinco tipos de viajantes vão todos os homens pela jornada a vida, os mais baixos como seres puramente passivos, os mais elevados como os que agem e se exprimem inteiramente, sem nenhum resíduo de eventos internos (NIETZSCHE, 2008, p. 109).

Tanto a passagem da vida de Sócrates quanto as metáforas de Pitágoras e Nietzsche podem ser transpostas para o contexto das visitas a espaços educativos de caráter público, espaços não formais de educação ou para qualquer espaço da cidade que se converta em um espaço educativo em termos culturais, científicos, políticos, econômicos etc. Tudo depende do olhar que se tem sobre a cidade, em geral, ou sobre cada espaço da cidade, em particular. Para que isso seja possível, as vivências proporcionadas nesses espaços devem propor o alcance do olhar do último viajante de Nietzsche. Mas isso só será possível quando educador e educando forem sujeitos que se eduquem e cresçam juntos. Nessa linha de pensamento, lembramos das ideias de Freire (1987, p. 39), quando conclui que "Ninguém educa ninguém. Ninguém educa a si mesmo. Os homens se educam entre si mediatizados pelo mundo". Assim, podemos afirmar que o cidadão, habitante da cidade, ao apropriar-se dos conceitos científicos e culturais, com a mediação do educador, atinge o estágio de cidadão mais completo, integrado à cidade e à sociedade. 
Acreditamos, porém, que não existe olhar neutro do mundo que nos cerca, em especial para os viajantes com espírito "mais elevado". Todo processo pedagógico está repleto de ingredientes ideológicos, políticos e culturais que se fazem presentes no ato educativo e marcam a forma de falar, agir, sentir e ver o mundo, seja por parte dos educandos ou dos educadores.

É dessa forma que elencamos aqui, como exemplo, uma perspectiva que ajuda a olhar e atualizar a potência educativa que existe em toda cidade e em cada espaço da cidade. Denominaremos essa questão como sendo uma leitura da cidade, reflexões sobre a cidade. 


\section{REFLEXÕES SOBRE A CIDADE}

Michel Foucault (2001; 2012), em obras como "Vigiar e punir" e "Microfísica do poder", traz estudos interessantes sobre alguns espaços, como a cidade operária, as prisões, os conventos, os hospitais. Os estudos de Foucault, muitos deles inspirados em Nietzsche, revelam as relações de poder que existem nos espaços. Ele estuda o "Panopticon de Bentham", aquela arquitetura feita de tal forma que um só homem pode controlar as ações de muitos, bem ao modo das sociedades contemporâneas, na qual o grande irmão (Big Brother) acompanha a todos (Sorria, você está sendo filmado!). Em "Microfísica do Poder" (XIV - O olho do poder) Foucault escreve:

Mas, se a idéia do panopticon é anterior a Bentham, na verdade foi Bentham que realmente a formulou. E batizou. A própria palavra "panopticon" é fundamental. Designa um princípio de conjunto. Sendo assim, Bentham não imaginou simplesmente uma figura arquitetural destinada a resolver um problema específico, como o da prisão, o da escola ou o dos hospitais. Ele anuncia uma verdadeira invenção que ele diz ser o "ovo de Colombo". E, na verdade, é aquilo que os médicos, os penalistas, os industriais, os educadores procuravam que Bentham lhes propõe: ele descobriu uma tecnologia de poder própria para resolver os problemas de vigilância. Algo importante a ser assinalado: Bentham pensou e disse que seu sistema ótico era a grande inovação que permitia exercer bem e facilmente o poder. Na verdade, ela foi amplamente utilizada depois do final do século XVIII. Mas os procedimentos de poder colocados em prática nas sociedades modernas são bem mais numerosos, diversos e ricos. Seria falso dizer que o princípio da visibilidade comanda toda a tecnologia do poder desde o século XIX (FOUCAULT, 2012, p. 116).

O autor também estuda as diversas formas de resistência a essa estrutura e como o poder se divide na sociedade, na cidade. Foucault descreve uma série atos de luta e resistência, à indústria, à medicina, às prisões entre outras, às formas de controle impostas pelo "panopticon". Afirma, por exemplo, que: 
É preciso analisar o conjunto das resistências ao panopticon em termos de tática e de estratégia, vendo que cada ofensiva serve de ponto de apoio a uma contra-ofensiva. A análise dos mecanismos de poder não tende a mostrar que o poder é ao mesmo tempo anônimo e sempre vencedor. Trata-se ao contrário de demarcar as posições e os modos de ação de cada um, as possibilidades de resistência e de contra-ataque de uns e de outros (FOUCAULT, 2012, p. 126).

Se quisermos dar um exemplo mais próximo de nós, utilizando Foucault, poderemos fazer uma leitura dos locais religiosos de peregrinação popular como sendo um local de resistência a um sistema de saúde que massacra o povo. Em 'Microfísica do Poder', o olhar de Foucault para esses locais, espaços e situações refere-se ao entendimento das seguintes questões:

Que significado tem a peregrinação de Lourdes, desde o final do século XIX até hoje, para os milhões de peregrinos pobres que aí vão todos os anos, senão uma espécie de resistência difusa à medicalização autoritária de seus corpos e doenças? Em lugar de ver nessas práticas religiosas um fenômeno residual de crenças arcaicas ainda não desaparecidas, não serão elas uma forma atual de luta política contra a medicalização autoritária, a socialização da medicina, o controle médico que se abate essencialmente sobre a população pobre; não serão essas lutas que reaparecem nessas formas aparentemente arcaicas, mesmo se seus instrumentos são antigos, tradicionais e supõem um sistema de crenças mais ou menos abandonadas? O vigor dessas práticas, ainda atuais, é ser uma reação contra essa social medicine, medicina dos pobres, medicina a serviço de uma classe, de que a medicina social inglesa é um exemplo (FOUCAULT, 2012, p. 57).

Para citar outro estudioso que faz sua leitura da cidade, temos Henry Lefebvre (2001), em seu livro "Direito à cidade". O autor afirma, na apresentação desse texto, que a cidade é hoje o grande laboratório do homem. Avalia de forma crítica aquilo que se manifesta na cidade 
moderna marcada pelo modo de produção capitalista. Lefebvre discorre sobre a necessidade de se desenvolver uma "Ciência da Cidade". Busca fugir de uma forma reducionista de ver a cidade e, a partir de Nietzsche, no anuncio que fez da "morte de Deus", ele observa na cidade a morte do humanismo e a crença na ciência e na técnica. Defende a necessidade de se voltar para a grandeza do homem, como faz Nietzsche, e nota, na esteira de Marx, que a solução da transformação das cidades está na classe operária. Defende o direito à cidade como o próprio direito à vida. Em seu texto, "A filosofia e a cidade", afirma:

Para a meditação filosófica que visa uma totalidade através da sistematização especulativa, isto é, para a filosofia clássica, de Platão e Hegel, a Cidade foi muito mais do que um tema secundário, um objeto dentre outros [...] A Grande Cidade e a Cidade não foram, para os filósofos e para a filosofia, uma simples condição objetiva, um contexto sociológico, um dado externo. Os filósofos pensaram a Cidade, trouxeram a vida urbana para a linguagem e para o conceito (LEFEBVRE, 2001, p. 35).

Esses são alguns exemplos clássicos. Poderíamos ainda ilustrar essas discussões com uma série de amostras que utilizam teorias das mais diversas para lançar outros olhares sobre a cidade que educa. Uma experiência foi apresentada por Sgarbi e Gomes (2000), que, por meio de um olhar pedagógico, publicaram um pequeno livro com quinze crônicas, ilustradas por quinze aquarelas, cada uma revelando o potencial educativo de espaços (calçadas e ruas, bares, campo de futebol, árvore histórica, festas...) de um bairro de periferia da cidade de Taubaté, no Vale do Paraíba, no Estado de São Paulo, no Brasil. A partir do dia a dia do bairro, registrado nos textos e nas aquarelas e olhado à luz de uma das vertentes do pensamento existencialista, os autores deram o pontapé inicial para a reflexão sobre "o lado do Belém [nome do Bairro que contemplaram] que existe em cada cidade interiorana, não só do Brasil" (SGARBI; GOMES, 2000, p. 07). Naquele mesmo ano em que o pequeno livro foi publicado, uma escola de ensino fundamental do bairro, por iniciativa de um professor de Geografia, desenvolveu um projeto que desencadeou um processo educativo a partir daqueles espaços educacionais que, em sentido amplo, dialogavam com o espaço educacional em sentido 
restrito.

Outro olhar sobre a cidade que educa pode ser encontrado no texto de Araújo (2011), ao discorrer sobre a cidade como espaço público de educação e de afirmação da cidadania. A autora apresenta uma experiência vivenciada em Vitória/ES, Brasil, a partir de autores como Nilton Santos e Paulo Freire, entre outros. No texto Araújo (2011) faz uma leitura da cidade, tocando em questões delicadas que envolvem, por exemplo, a ética pública, denunciando a busca de satisfação das necessidades momentâneas, individualistas, clientelistas, corporativistas e pontuais que infelizmente são percebidas em administrações públicas. Ela afirma categoricamente: “[...] a política para poder permanecer livre e humana deve constituir-se como uma experiência duradoura, na qual as atuais e futuras gerações possam com ela aprender a preservar e a renovar no mundo" (ARAÚJO, 2011, p. 142). Ao ler tal texto, reafirmamos nossa convicção de que é necessário que haja políticas públicas que, com seriedade, ajudem a construir uma cidade mais humana em diálogo com uma escola cidadã.

Mantendo o diálogo com alguns dos pensadores clássicos citados, à luz dos quais poderemos compreender nossa realidade, vamos discorrer de forma específica sobre duas outras perspectivas de leitura da cidade: a marxiana e a freireana.

\subsection{A cidade na perspectiva marxiana}

Na perspectiva marxiana, a sociedade capitalista seria aquela dominada pelos imperativos dos lucros, os quais criam necessidades falsas, através da manipulação dos consumidores, sem gerar felicidade, satisfação ou harmonia. Nesse sentido, a cidade na sociedade capitalista adquire também características voltadas para a mercantilização. Ela fica submetida às mediações relacionadas à ampliação dos lucros, ou seja, seu espaço também se transforma em mercadoria. Passa a ser a cidade-empresa (HALL, 2005), isto é, a cidade com vistas a alavancar o movimento de valorização do capital, por meio da privatização de bens públicos e da apropriação de verbas públicas sob a forma de investimentos em parcerias cujos benefícios se destinam ao Capital. A cidade é o lócus próprio da sociedade 
moderna, da economia capitalista. Os elementos que a compõem são necessários à vida, porém circulam como mercadoria. Para Marx (2003, p. 135),

No mundo moderno, todos são, a um só tempo, membros da escravidão e da comunidade. Precisamente a escravidão da sociedade burguesa é, em aparência, a maior liberdade, por ser a independência aparentemente perfeita do indivíduo, que toma o movimento desenfreado dos elementos estranhados de sua vida [...] por sua própria liberdade, quando na verdade é, muito antes, sua servidão e sua falta de humanidade completas e acabadas.

Por conseguinte, o Capital transforma o solo urbano em instrumento da própria acumulação. As cidades, principalmente as mais cosmopolitas, são planejadas para dar circulação ao automóvel, para abrigar eventos artísticos, culturais e esportivos de grande porte, para sediar os negócios mais rentáveis, para consolidar o processo de acumulação do Capital. Mas, ao mesmo tempo, a cidade é o lugar onde vive o maior número de pessoas, é nela que se expressam com maior vivacidade as principais contradições que caracterizam o modelo capitalista de sociedade, expondo conflitos e crises com relativa periodicidade (CURY, s/d).

Os 'melhoramentos' urbanos que acompanham o progresso da riqueza, a demolição de quarteirões mal construídos, a construção de palácios para bancos, lojas, etc., o alargamento de ruas para o tráfego comercial e para as carruagens de luxo, o estabelecimento de linhas para bondes, etc., desalojam evidentemente os pobres, expulsando-os para refúgios cada vez piores e mais abarrotados de gente (MARX, 1988, p. 764).

Nesse sentido, é preciso evidenciar as possibilidades de transformação das cidades. Cabe pensar em uma nova organização dos espaços e dos tempos das cidades, na perspectiva da instauração de práticas educadoras orientadas para o processo de humanização, e não sob a efígie capitalista de mercantilização das cidades. 
Sobre o processo de humanização do homem, Marx aponta que, para confirmar a sua humanidade,

O homem se apropria da sua essência omnilateral [em todas as dimensões] de uma maneira omnilateral [de uma maneira compreensiva], portanto, como um homem total (MARX, 2004, p. 108).

Todas as relações humanas com o mundo - ver, ouvir, cheirar, saborear, sentir, pensar, contemplar, querer, agir, amar, em resumo, todos os órgãos da sua individualidade assim como aqueles que, na sua forma imediata, são comuns a todos - encontram-se na sua atitude objetiva ou na atitude para o objeto como uma adoção deste último. A adoção da realidade humana e sua atitude para com o objeto constituem a manifestação da realidade humana: a atividade e sofrimento humanos, para sofrer, encarados humanamente, representam a auto-satisfação do homem (MARX; ENGELS, 1986, p. 77).

Assim, pela presença da cultura, tornamo-nos humanos. Nas palavras de Marx (2001, p. 143144):

Só por meio da riqueza objetivamente desenvolvida do ser humano é que em parte se cultiva e em parte se cria a riqueza da sensibilidade subjetiva humana (o ouvido musical, o olho para a beleza das formas, em resumo, os sentidos capazes de satisfação humana e que se confirmam como capacidades humanas).

Portanto, o fundamental é perceber que o processo de humanização se relaciona com a criação de diferentes produções humanas, dentre elas a cidade. Tal processo está relacionado também a apropriação dessas produções, ou seja, quando o sujeito as incorpora em suas vivências em meio a relações sociais. O grande desafio é pensar em modos transformadores de apropriação da cidade como espaço de potenciais mediações educativas. Pensar em modos sensíveis de possibilitar que os sujeitos se apropriem da cidade, sem deixar de perceber que a cidade reflete a organização social capitalista.

Assim, lutar por uma cidade melhor é, antes de tudo, lutar por uma sociedade mais justa, implicando mudanças nas relações econômico-sociais. A cidade deve ser, portanto, o lugar do exercício pleno da cidadania, dando condições para que os sujeitos se desenvolvam 
material e culturalmente, ou seja, que se constituam as máximas potencialidades do gênero humano.

\subsection{Cidades educativas na visão de freireana}

Freire (2007) traz no texto "Educação permanente e as cidades educativas" profícuas contribuições sobre esse assunto. Para ele, a educação é um processo permanente, e a vida das cidades acolhe a prática educativa, a prática social, mas também se constitui, através de suas múltiplas atividades. A prática educativa refere-se, portanto, à "programas em que a leitura crítica de mundo se funda numa prática educativa crescentemente desocultadora de verdades. Verdades cuja ocultação interessa às classes dominantes da sociedade" (FREIRE, 2007, p. 21). O indivíduo, nesse processo, constitui-se como um ser que tem por vocação a humanização, porém se confronta com o incessante desafio da desumanização.

Aprender e ensinar fazem parte da existência humana, histórica e social, "como dela fazem parte a criação, a invenção. A linguagem, o amor, o ódio, o espanto, o medo, o desejo, a atração pelo risco, a fé, a dúvida, a curiosidade, a arte, a magia, a ciência, a tecnologia. $E$ ensinar e aprender cortando todas estas atividades humanas" (FREIRE, 2007, p. 22).

Em sua concepção ontológica (estudo do ser), Freire aponta que foi devido à capacidade de "dizer o mundo" que o ser humano, na medida em que transformava o mundo, na medida em que o reinventava, tornou-se tanto um sujeito que ensina quanto um aprendiz. Ele foi se constituindo como sujeito de uma prática que se tornou política, gnosiológica (que estuda o conhecimento humano), estética e ética. Nesse sentido, a educação não se constitui como ideologia, agregada aos interesses econômicos, mas está ligada à constante busca, indagação e curiosidade humana. Tal educação liga-se à consciência de finitude humana, principalmente à consciência de que é possível saber mais. Por isso, a formação humana é permanente.

Freire considera que a educação é um processo de conhecimento, de ensino, de 
aprendizagem que, ao longo da trajetória da humanidade, tem como vocação a humanização, pois o ser humano jamais para de educar-se. Contudo, tal direito é alijado diante das demandas do capital. Segundo o autor, para que tal direito se assente, seria preciso que os Movimentos Populares enfatizassem sua luta política para pressionar o Estado a cumprir o seu dever. "Jamais deixá-lo em sossego, jamais eximi-lo de sua tarefa pedagógica, jamais permitir que as classes dominantes durmam em paz" (FREIRE, 2007, p. 24).

Diante da necessidade ontológica educativa, a cidade constitui-se também como espaço educador.

A cidade se faz educativa pela necessidade de educar, de aprender, de ensinar, de conhecer, de criar, de sonhar, de imaginar que todos nós, mulheres e homens, impregnamos suas ruas, suas praças, suas fontes, suas casas, seus edifícios, deixando em tudo o selo de certo tempo, estilo, o gosto de certa época. A cidade é cultura, criação, não só pelo que fazemos nela e dela, pelo que criamos nela e com ela, mas também é cultura pela própria mirada estética ou de espanto, gratuita que lhe damos. A cidade somos nós e nós somos a cidade (FREIRE, 2007, p. 25).

A tarefa educativa da cidade é atravessada pelos posicionamentos políticos, pela maneira que é exercido o poder na cidade, ou seja, a serviço de quem e de que estamos agindo. Tal tarefa se realiza por meio do tratamento de sua memória que se estende e se comunica com as novas gerações. "Seus museus, seus centros de cultura, de arte são a alma viva do ímpeto criador, dos sinais de aventura do espírito. Falam de épocas diferentes, de apogeu, de decadência, de crises, da força condicionante das condições materiais" (FREIRE, 2007, p. 26).

Para Freire, as reflexões suscitadas pela cidade devem fomentar discussões e sonhos relacionados à diminuição da desigualdade, da discriminação e que repensem essa democracia falsa que se relaciona à fome e ao analfabetismo.

As cidades educativas devem ensinar a seus filhos e aos filhos de outras cidades que as visitam, que não precisamos esconder a condição de judeu, de árabes, de alemães, de suecos, de norte-americanos, de brasileiros, de africanos, de latino-americanos de origem hispânica, de indígenas não 
importa de onde, de negros, de louros, de homossexuais, de crentes, de ateus, de progressistas, de conservadores, para gozar de respeito e de atenção (FREIRE, 2007, p. 27-28).

Segundo Freire, essa virtude da tolerância pode ser estimulada pela cidade e por suas instituições pedagógicas, culturais, científicas, artísticas, religiosas, políticas, financeiras, de pesquisa etc., para que as crianças e os adolescentes sejam desafiados a pensar e a discutir o direito de ser diferente, sem que isso signifique correr o risco de ser discriminado, punido ou banido da vida.

Na esteira dos filósofos gregos, Nietsche, Foucault, Lefebvre, Marx, Freire e de tantos outros que lançaram seu olhar sobre a cidade, afirmamos que o educador deve contemplar a cidade, pensar a cidade, extrair de cada espaço dela as lições que possam dar mais vida às pessoas, humanizar os cidadãos. Essas são algumas chaves de leitura da cidade e de seus espaços. 


\section{ESCOLA, CIDADE, EDUCAÇÃO E CIDADANIA}

\subsection{Cidade, escola e educação}

A cidade educa sempre no sentido amplo de educação, a escola educa não só no sentido amplo, mas especialmente no sentido restrito. Na modernidade, conhecida também como sociedade urbano industrial, a escola ganha um papel de destaque, já que

[...] a escola educa para a cidade e é marcada pelas características da vida urbana tendo em vista suas necessidades. [...] Escola e cidade são mundos de tal modo imbricados, como são imbricados alunos, professores e pais [...] imbricados como são, determinam-se mutuamente: a cidade educa a escola e a escola educa a cidade. Na verdade a escola é uma invenção da cidade. A escola é a cidade educando intencional e formalmente seus membros para si mesma. [...] As relações e inter-relações que ocorrem na cidade são educativas por si mesmas. A escola, dentro da cidade, promove relações desejadas, estudadas, intencionais [...] (LORIERI, 2006, p. 93).

Nessa linha de pensamento, não é possível ver a escola separada da cidade. A escola é da cidade, na cidade e para a cidade e, nesse sentido, a educação será sempre um ato político. As cidades são "verdadeiros ninhos de humanização e... de riscos de desumanização! As escolas são pedaços privilegiados desses ninhos! Que podem ajudar na humanização, mas podem também servir ao que desumaniza" (LORIERI, 2006, 93). Aos educadores cabe a tarefa de cuidar para que a humanização seja uma constante na cidade e na escola.

\subsection{Escola e cidadania}

$\mathrm{Na}$ mesma linha de pensamento anterior destacada, podemos afirmar que existe uma ligação íntima entre a definição de educação e os fins da educação. Assim como a definição de educação, os fins, ou objetivos educacionais, são definidos de várias formas e em geral refletem as condições sociais, históricas, políticas e econômicas dos diversos tempos e lugares. Reboul (1980) considera que encontrar os fins da educação é um problema filosófico por excelência. 
Diante do momento sócio, histórico, político e econômico do Brasil e a partir das necessidades atuais da cidade faz-se necessário buscar a resposta sobre os fins da educação em sentido restrito na própria legislação do país. Vejamos.

Citamos, no começo deste texto, o artigo de número 205 da Constituição, que aponta a educação como um direito de todos e dever do Estado e da família. Já no artigo 2o da Lei de Diretrizes e Bases da Educação Nacional lemos: "A educação, dever da família e do Estado inspirada nos princípios de liberdade e nos ideais de solidariedade humana, tem por finalidade o pleno desenvolvimento do educando, seu preparo para o exercício da cidadania e sua qualificação para o trabalho" (BRASIL, 1996). Sendo ainda muito amplos esses conceitos, tomemos como exemplo o que dizem as Diretrizes Curriculares Nacionais para a Educação Básica:

A Educação Básica é direito universal e alicerce indispensável para a capacidade de exercer em plenitude o direto à cidadania. É o tempo, o espaço e o contexto em que o sujeito aprende a constituir e reconstituir a sua identidade, em meio a transformações corporais, afetivoemocionais, socioemocionais, cognitivas e socioculturais, respeitando e valorizando as diferenças (BRASIL, 2013, p. 17, grifo nosso).

Em continuidade essa finalidade, as Diretrizes Curriculares Nacionais para o Ensino Fundamental afirmam no artigo $7^{\circ}$ :

De acordo com esses princípios, e em conformidade com o art. 22 e o art. 32 da Lei no 9.394/96 (LDB), as propostas curriculares do Ensino Fundamental visarão desenvolver o educando, assegurar-lhe a formação comum indispensável para o exercício da cidadania e fornecer-lhe os meios para progredir no trabalho e em estudos posteriores, mediante os objetivos previstos para esta etapa da escolarização [...] (BRASIL, 2013, p. 131, grifo nosso). 
Na mesma linha de pensamento, as Diretrizes Curriculares Nacionais para o Ensino Médio, no artigo $4^{\circ}$, afirmam:

As unidades escolares que ministram esta etapa da Educação Básica devem estruturar seus projetos político-pedagógicos considerando as finalidades previstas na Lei no 9.394/96 (Lei de Diretrizes e Bases da Educação Nacional):

I - a consolidação e o aprofundamento dos conhecimentos adquiridos no Ensino Fundamental, possibilitando o prosseguimento de estudos;

II - a preparação básica para o trabalho e a cidadania do educando para continuar aprendendo, de modo a ser capaz de se adaptar a novas condições de ocupação ou aperfeiçoamento posteriores; [...] (BRASIL, 2012, grifo nosso).

Tendo em vista os destaques que colocamos no início deste subitem e os recortes feitos anteriormente, podemos concluir que a discussão sobre o binômio trabalho/cidadania é algo central para a compreensão de quais são os verdadeiros fins da educação hoje no Brasil. A grande preocupação das diretrizes nacionais destacadas é apresentar a concepção de cidadania e os princípios democráticos que a norteiam. Mas, no diálogo entre escola e cidade, qual deve ser nosso entendimento de cidadania?

Gadotti (2006, p. 134) discute essa questão, afirmando que "cidadania é essencialmente consciência de direitos e deveres e exercício da democracia [...]". O autor discorre sobre os direitos civis, sociais e políticos, reconhecendo que esse direito é ambíguo e que a cidadania apresentada na Declaração dos Direitos do Homem e do Cidadão de 1789 foi uma conquista liberal, que já não mais responde à complexidade dos dias atuais.

Com a ampliação dos direitos, nasce também uma concepção mais ampla de cidadania. De um lado, existe uma concepção consumista de cidadania (direito de defesa do consumidor) e, de outro, uma concepção plena, que se 
manifesta na mobilidade da sociedade para a conquista de novos direitos e na participação direta da população na gestão da vida pública [...] (GADOTTI, 2006, p. 134).

Ao considerar que os fins da educação estão intimamente ligados ao exercício da cidadania deve haver um diálogo contínuo entre cidade e escola para que possamos trilhar o caminho para a construção de uma escola cidadã que se desenvolve dentro de uma cidade educativa. A escola não pode desconsiderar a cidade, pois ela é um espaço público de educação e de afirmação da cidadania (ARAÚJO, 2011).

\subsection{Cidade educadora ou Cidade educativa}

Já que consideramos todo ato educacional como um ato político e que pontuamos que ele não é neutro, uma vez que tomamos uma posição nesta nossa reflexão sobre cidade, educação e escola, faz-se necessário voltar a uma questão levantada na introdução deste texto, a de que os esforços por "cidade educadora" visavam a ampliação e o reforço da sociedade capitalista pela via de se delegar à sociedade civil a responsabilidade de implementar e executar políticas sociais. Mesmo considerando que o termo "cidade educadora" possa ser um termo polissêmico como tantos outros, queremos reafirmar que, ao pensar o potencial educativo da cidade, temos uma perspectiva bem diferente da que anteriormente foi colocada. Explicitemos esta nossa preocupação.

No artigo 37, parágrafo segundo, das Diretrizes Curriculares Nacionais para o Ensino Fundamental de nove anos, no que tange a escola em tempo integral, é muito claro o apoio às atividades escolares em espaços distintos da cidade, desde que isso esteja de acordo com os projetos políticos pedagógicos da escola. Essa questão vem reforçar todas as nossas conviç̧ões, aquelas que explicitamos no texto em tela. Na íntegra o parágrafo dois do artigo supracitado afirma que:

As atividades serão desenvolvidas dentro do espaço escolar conforme a disponibilidade da escola, ou fora dele, em espaços distintos da cidade ou 
do território em que está situada a unidade escolar, mediante a utilização de equipamentos sociais e culturais aí existentes e o estabelecimento de parcerias com órgãos ou entidades locais, sempre de acordo com o respectivo projeto político-pedagógico (BRASIL, 2013).

Na sequência, o parágrafo número três afirma que, ao restituir a condição de ambiente de aprendizagem à comunidade e à cidade, a escola estará contribuindo para a construção de redes sociais e de cidades educadoras (BRASIL, 2013). Esse parágrafo é explicitado também no Parecer CNE/CEB n. 11/2010 aprovado em 7 de julho de 2010, ao tratar da escola em tempo integral. Tal perspectiva é apresentada na lei, a partir das recomendações de órgãos internacionais, como a Unesco, por meio das Conferências Internacionais em prol da Educação para Todos, conforme apontamos no início deste artigo.

$\mathrm{Na}$ linha de pensamento que estamos desenvolvendo, assumir a perspectiva das "cidades educadoras" é assumir a postura daqueles que buscam "contribuir" com a educação nos países que "necessitam" se adequar ao contexto de globalização do mercado. Cientes de que a educação é um ato político, não neutro e ideológico descartamos o discurso da construção das "cidades educadoras" e reafirmamos nossa crença na perspectiva da "cidade educativa" (nas palavras de Freire) ou de modo mais amplo, da "educação na cidade", como sendo aquela que promove a humanização, o empoderamento e a construção da cidadania plena que visa à transformação social. 


\section{CONSIDERAÇÕES CONCLUSIVAS}

As ideias trazidas neste artigo estão em processo. Assim sendo, não queremos finalizar nossas reflexões ao responder diretamente às nossas questões iniciais. Preferimos deixar para cada leitor, que, mais do que leitor, é educador, autor e resultado de múltiplas determinações (LORIERI, 2006), o convite de continuar refletindo conosco. Cada um com seu olhar sobre a realidade. Assim, deixamos aqui nossas reticências com as mesmas perguntas que iniciamos nosso texto, convidando-o ao diálogo: qual potencial transformador da realidade reificada tem a Cidade? Que estratégias podem ser pensadas para que a Cidade contribua com reflexões e com a transformação da realidade? Como pode a Cidade contribuir com o processo humanizador dos sujeitos? Quais são os caminhos para construirmos uma escola cidadã em diálogo com uma cidade educativa?

Acreditamos que tais reflexões precisam ser realizadas antes, durante e depois de todas as intervenções educativas relacionadas com a cidade. Desse modo, poderemos assegurar que nossas ações possam contribuir com a emancipação e com a humanização de nossos educandos, na perspectiva de construir uma sociedade menos desigual. Como educadores, precisamos extrair de cada espaço da cidade, nos modos do viajante "elevado" nietzschiano, conhecimentos que possam contribuir para que todos os sujeitos se constituam as máximas possibilidades do gênero humano. 


\section{REFERÊNCIAS}

AGAZZI, Aldo (Org.). Educazione e società nel mondo contemporaneo. Brescia: La Scuola, 1965.

ARAÚJO, Vânia Carvalho de. A cidade como espaço público de educação e de afirmação da cidadania: a experiência de Vitória/ES Brasil. RBPAE, v. 27, n. 1. p. 135-148, jan/abr. 2011.

BRANDÃO, Carlos Rodrigues. A educação como cultura. São Paulo: Brasiliense, 1986.

BRASIL. Constituição da República Federativa do Brasil. Brasília, Senado, 1988. Disponível em: <ibge.gov.br/home/estatistica/populacao/caracteristicas_raciais/notas_tecnicas.pdf>. Acesso em: 20 jun. 2014.

BEILLEROT, Jacky. A sociedade pedagógica. Porto: Rés, 1985.

BRASIL. Senado Federal. Lei de Diretrizes e Bases da Educação Nacional: no 9394/96. Brasília: 1996.

BRASIL. MEC. Resolução CNE/CEB 2/2012. Diretrizes Curriculares Nacionais para o Ensino Médio. Diário Oficial da União, Brasília, 31 de janeiro de 2012, Seção 1, p. 20. Disponível em: <file:///D:/Documentos/Downloads/rceb002_12.pdf>. Acesso em: 20 jun. 2014.

BRASIL. MEC. SEB. DICEI. Diretrizes Curriculares Nacionais Gerais da Educação Básica / Ministério da Educação. Secretaria de Educação Básica. Diretoria de Currículos e Educação Integral. Brasília: MEC, SEB, DICEI, 2013.

CARRANO, Paulo César Rodrigues. Juventudes e cidades educadoras. Rio de Janeiro: Petrópolis, 2003.

CHAUÍ, Marilena. Convite à filosofia. São Paulo: Editora Ática, 1999.

CHISTÉ, Priscila de Souza. Educação estética na educação profissional: mediações das obras de arte de Raphael Samú. Tese (Doutorado em Educação) - Universidade Federal do Espírito Santo, Vitória, 2013.

CURY, Vania Maria. Marx, Engels e as cidades no capitalismo. Disponível em: <unicamp.br/cemarx/ANAIS\%20IV\%20COLOQUIO/comunica\%E7\%F5es/GT2/gt2m1c3.pdf>. Acesso em: 11 jul. 2014.

FAURE, Edgar. Aprender a ser. São Paulo: Difusão Editorial do Livro. 1977.

FOUCAULT, Michel. Vigiar e punir: nascimento da prisão. Petrópolis: Vozes, 2001. . Microfísica do poder. Rio de Janeiro: Graal, 2012.

FREI BETTO. Passeio socrático. 1 de mar. 2011. Disponível em: 
www.ufscar.br/consusol/arquivos/PASSEIO\%20SOCRATICO.doc. Acesso em: 20 jun. 2014.

FREIRE, Paulo. Pedagogia do oprimido. 17 ed. 23 reimpressão. Rio de Janeiro: Paz e Terra, 1987.

Política e educação. São Paulo: Vila das Letras, 2007.

GADOTTI, Moacir. A questão da educação formal/não-formal. 2005. Disponível em: <virtual.ufc.br/solar/aula_link/Ilpt/A_a_H/estrutura_politica_gestao_organizacional/aula_01 /imagens/01/Educacao_Formal_Nao_Formal_2005.pdf>. Acesso em: 11 jul. 2014.

. A escola na cidade que educa. Cadernos Cenpec: educação e cidade, 2006, n. 1, p. 133 - 139. Disponível em: <file://D:/Documentos/Downloads/caderno-cenpec-1.pdf>. Acesso em: 20 jun. 2014.

GRAMSCl, Antonio. Concepção Dialética da História. Rio de Janeiro: Civilização Brasileira, 1984.

HALL, Peter. Cidades do Amanhã: uma história intelectual do planejamento e do projeto urbanos no século XX. São Paulo: Perspectiva, 2005.

HÚSEN, T. Nuévo análisis de la sociedade del aprendizage, Barcelona: Ed. Paidós, MEC, 1988.

LEFEBVRE, Henry. 0 direito à cidade. São Paulo: Centauro, 2001.

LORIERI, Marcos Antônio. Escola e cidade se educam. Cadernos Cenpec: educação e cidade, 2006, n. 1, p. 133 - 139. Disponível em: <file://D:/Documentos/Downloads/cadernocenpec-1.pdf>. Acesso em: 20 de jun. 2014.

MARX, Karl; ENGELS, Friedrich. Sobre literatura e arte. São Paulo: Global editora, 1986.

. O Capital. Volume 1, livros I e II. Tradução de Reginaldo Sant'Anna. 12a ed. Rio de Janeiro: Bertrand Brasil, 1988.

. Manuscritos econômico-filosóficos. Tradução de Jesus Ranieri. São Paulo: Editora Martin Claret Ltda, 2001.

- A crítica absoluta ou a crítica conforme o senhor Bruno - terceira campanha da crítica absoluta. Em: MARX, K. e ENGELS, F. A Sagrada Família. São Paulo: Boitempo, 2003.

- Manuscritos econômico-filosóficos. Tradução de Jesus Ranieri. São Paulo:

Boitempo, 2004.

NIETZSCHE, Friedrich. Obras Completas. Buenos Aires: Aguilar Editor, 1950.

Humano, demasiado humano II. São Paulo: Companhia das Letras, 2008.

PINTO, Álvaro Vieira. Sete lições sobre educação. São Paulo: Cortez, 1997. 
REBOUL, Olivier. Filosofia da Educação. 3. ed. São Paulo: Nacional, 1980.

SAVIANI, Dermeval. Pedagogia Histórico-Crítica. Campinas: Editora Autores Associados, 1997.

SGARBI, Antonio Donizetti; GOMES, Fátima. Belém “que te quero bem". Belo Horizonte: 0 Lutador, 2000.

VALOURA, Leila de Castro. Paulo Freire, o educador brasileiro autor do termo empoderamento, em seu sentido transformador. Disponível em: <tupi.fisica.ufmg.br/michel/docs/Artigos_e_textos/Comportamento_organizacional/empowe rment_por_paulo_freire.pdf>. Acesso em 27 de junho de 2014.

VILLAR, Maria Belém Caballo. A cidade educadora. Lisboa: Instituto Piaget, 2001. 